\title{
DECOLONIZAÇÃO, SUL GLOBAL E COLONIALIDADE DO PODER ${ }^{1}$
}

\author{
Decolonialism, Global South and Coloniality of Power
}

\author{
Marina DE CHIARA \\ Universidade "L'Orientale" di Napoli \\ mdechiara@unior.it \\ https://orcid.org/0000-0003-3384-7649 \\ Tradução de Adriana Tulio BAGGIO \\ Universidade Federal do Paraná \\ atbaggio@gmail.com \\ https://orcid.org/0000-0002-5016-1289
}

RESUMO: Este texto é a versão em português de "Decolonizzazione, Sud del mondo e colonialità del potere", de Marina De Chiara, capítulo do livro Sud immaginari. Colonialità del potere, chicane ribelli, interferenze blues, publicado na Itália em 2019 e organizado pela mesma autora. $\mathrm{O}$ artigo apresenta os principais conceitos advindos de perspectivas críticas sobre a modernidade como produto da empresa colonial e o sistema dela resultante, chamado por Aníbal Quijano de colonialidade do poder, ainda em operação. Tais reflexões são consideradas úteis para se pensar a oposição epistemológica entre norte e sul do mundo, fratura que atua inclusive no corpo das nações, promovendo uma forma de colonialismo interno. Nesse sentido, De Chiara faz referência às questões italianas, especialmente em relação à marcada divisão entre o mezzogiorno (o sul) e o norte do país desde a Unificação (1861), às migrações internas do sul ao norte no século XX e, mais recentemente, à migração do continente africano à Itália, que tem no sul italiano o seu ponto de chegada. Dessa forma, De Chiara mostra a produtividade de um pensamento subalterno - oriundo especialmente de grupos de estudos asiáticos e latino-americanos - para se pensar questões do Norte global. PALAVRAS-CHAVE: Border theory; Colonialidade do poder; Colonialismo interno; Políticas imigratórias.

ABSTRACT: This text is the Portuguese version of Marina De Chiara's "Decolonizzazione, Sud del mondo and colonialità del potere",

\footnotetext{
${ }^{1}$ Publicação original: DE CHIARA, Marina. Decolonizzazione, Sud del mondo e colonialità del potere. In: DE CHIARA, Marina (org.). Sud immaginari. Colonialità del potere, chicane ribelli, interferenze blues. Mantova: Universitas Studiorum, 2019. p. 11-32.
} 
a chapter of the book Sud immaginari. Colonialità del potere, chicane ribelli, interferenze blues, published in Italy in 2019 and edited by the same author. The article presents the main concepts that come from critical perspectives on modernity as a product of the colonial enterprise and the system which is its result, called "coloniality of power" by Aníbal Quijano - a system that is still in operation. Such reflections are considered useful for thinking about the epistemological opposition between the North and the South of the world, a fracture that even operates in the body of nations, promoting a form of internal colonialism. In this sense, De Chiara refers to Italian issues, especially concerning: the marked division between the mezzogiorno (the south) and the north of the country that operates since Unification (1861); the Italian internal migrations from south to north in the 20th century; and, more recently, the migration from the African continent to Italy, which has its point of arrival in southern Italy. In this way, De Chiara shows the productivity of the subaltern studies - especially the ones from Asian and Latin American study groups - to think about issues of the Global North. KEYWORDS: Border theory; Coloniality of power; Immigration policies; Internal colonialism.

Dipesh Chakrabarty, autor do afortunado estudo dos anos 2000, Provincializzare l'Europa, recorda, em um artigo publicado em 2009 no Critical Inquiry, que termos como globalização, local, global e glocal entraram poderosamente no cenário das ciências sociais e humanísticas nos anos 1990 (Chakrabarty, 2009).

É impossível hoje pensar nas ciências sociais sem se referir a esses termos, inseridos no jargão da sociologia (mas não só) através de pensadores como Immanuel Wallerstein, Talal Asad, Arif Dirlik, James Clifford, Homi Bhabha, o próprio Dipesh Chakrabarty e muitos outros. Por esse motivo, o vocabulário clássico dos estudos culturais e dos estudos pós-coloniais revela-se, em certo sentido, carente de noções que são, por sua vez, tidas como palavras-chave, keywords do pensamento teórico ${ }^{2}$, dentre elas decolonização e

\footnotetext{
${ }^{2}$ Palavras-chave: um vocabulário de cultura e sociedade, de Raymond Williams, é um texto de 1976 (WILLIAMS, 2007). Nessa espécie de continuação ideal de Cultura e sociedade, de 1958 (WILLIAMS, 2011) - no qual o autor explorava novos termos que começavam a fazer parte do léxico moderno, focalizando em particular os conceitos de industry, democracy, class, culture e art -, o estudioso continua a se interrogar a respeito da ideia de englishness sem, no entanto, contemplar o cenário terminológico pós-colonial. Isso será remediado depois por Tony Bennett, Lawrence Grossberg e Meaghan Morris em New Keywords: A Revised Vocabulary of Culture and Society, de 2005. Dessa revisão estranhamente ficaram de fora termos que Williams havia inserido no seu volume, como myth, hegemony, agency, imperialism, native. Para uma observação acurada das diferenças entre os textos, veja-se o ensaio-resenha de Marina Vitale (2009), "Changing Vocabularies in Cultural and Postcolonial Studies".
} 
globalização. São esses dois termos que, por exemplo, o antropólogo James Clifford reconhece em sua "Introdução" a Returns: Becoming Indigenous in the Twenty-First Century (CLIFFORD, 2013) como novos instrumentos epistemológicos, uma toolkit [caixa de ferramentas] para uma reflexão atualizada sobre o real, ou seja, sobre como oferecer, hoje, uma descrição realista adequada do sistema-mundo (world-system) ${ }^{3}$.

Para expandir o raio da atual reflexão crítica sobre a modernidade globalizada e sobre o conceito de decolonização certamente contribuíram, junto a outros estudiosos, o grupo de pesquisa South Asian Subaltern Studies [estudos subalternos] (fundado por Ranajit Guha e composto por Gayatri Spivak, Dipesh Chakrabarty, Partha Chatterjee), como também o grupo de pesquisa Latin American Subaltern Studies (John Beverley, Ileana Rodríguez, José Rabasa, Walter Mignolo, Alberto Moreiras, Gabriela Nouzeilles), em uma palavra, os intelectuais do Global South [Sul Global] ${ }^{4}$.

Trata-se de perspectivas críticas cruciais para mostrar como a modernidade é, na realidade, produto da empresa colonial, que impôs um verdadeiro sistema, uma gramática fundadora, definida pelo sociólogo Aníbal Quijano como colonialidade do poder. A partir dessa e de outras instituições desconstroem-se importantes noções que estão sedimentadas há séculos no imaginário cultural ocidental. As assim chamadas "epistemologias de fronteira" (border theories), por exemplo, desmantelaram a noção de "fronteira" entendida como lugar de demarcação territorial, indícios de uma nítida separação entre culturas e povos, para mostrar, como sugerem as vozes teóricas de Gloria Anzaldúa ou de Guillermo Gómez-Peña, a sua complexa natureza fluida, aberta, sempre instável, porosa, onde acontecem contínuas trocas, misturas, mestiçagens entre línguas, pessoas, culturas. Através da lente da mestiçagem cultural, mesmo um conceito sólido, revestido de um tipo de aura "transcendental", como aquele de "americanidade", acaba sendo relido em uma perspectiva decolonial, dando vida à noção de "transamericanidade", cunhada pelo teórico José Saldívar.

As reflexões sobre a colonialidade do poder revelaram-se úteis para indagar também a oposição epistemológica entre norte e sul do mundo. Essa fratura de tipo colonial atua inclusive no corpo da própria nação, uma forma de colonialismo interno que ocorreu e ocorre na história italiana, como mostram as pesquisas sociológicas mencionadas nas

\footnotetext{
${ }^{3}$ Em Returns (CLIFFORD, 2013) coloca também em questão o termo realismo e o significado do qual se reveste nas ciências sociais. Ver, a propósito, De Chiara (2019b).

${ }^{4}$ Segundo Arif Dirlik (citado por SALDÍVAR, 2012, p. 231, nota 4), o termo Global South remonta aos anos 1970 e faz referência ao atraso político-econômico em relação à modernização ocidental (e já manifesto no período sucessivo à Segunda Guerra Mundial) de países que se desejaria englobar nas políticas neoliberais ocidentais (o pretenso progresso pós-capitalista).
} 
páginas finais deste texto. São questões que permanecem encontrando espaço nesta nossa modernidade ainda... colonial.

\section{MODERNIDADE COLONIAL}

Se é verdade que, em âmbito teórico, há uma certa tendência em se querer distinguir a metodologia crítica pós-colonial da metodologia crítica decolonial, esclarecese antes de tudo que não existem distinções nítidas e nem exclusivas ${ }^{5}$; ao contrário, dado o compartilhado interesse pela investigação das formas socioculturais da subalternidade, as duas perspectivas se entrecruzam continuamente, interrogando o estatuto de supremacia euro-ocidental no mundo. O que se pode seguramente reconhecer é uma importante diferença na geografia específica das referências teóricas os pensadores decoloniais são majoritariamente ligados a uma matriz latino-americana e, inspirados pela teologia da libertação, consideram o próprio trabalho como práxis de intervenção política nos territórios e não como exercício de tipo acadêmico, coisa que, por sua vez, é imputada aos pensadores pós-coloniais. Destes também se reprova a preponderância em se deter sobre sistemas e sobre as implicações do domínio dos impérios coloniais europeus do século XIX até a época atual, sem prestar a devida atenção ao acontecimento histórico que foi a conquista das Américas no século XVI. A referência indiscutível dos teóricos pós-coloniais seria Edward Said, com seu célebre Orientalismo, de 1978, que propunha a questão do Outro nos termos da redução colonial do outro a uma projeção das angústias e dos desejos do sujeito europeu. Já para os pensadores decoloniais, a relação primária a ser investigada na base da modernidade é aquela do sujeito europeu, o conquistador/colonizador, com o "nativo", o ameríndio. Poder-se-ia certamente objetar a respeito de cada um desses pontos, desmentindo completamente esses e outros argumentos que deveriam, na verdade,

\footnotetext{
${ }^{5}$ Sobre essa questão, remeto ao texto de Walter Mignolo (2000a), "(Post)Occidentalism, (Post) Coloniality, and (Post)Subaltern Rationality”. Veja-se também Inflexión decolonial, de Eduardo Restrepo e Axel Rojas (2010).
} 
revelar-se cruciais para se distinguir as duas perspectivas ${ }^{6}$. Mas, em todo caso, é de se auspiciar que essas ideias vindas das mais diferentes proveniências geográficas possam sempre dialogar entre si, em nome de um conhecimento desinteressado, e sem tender a uma competição sobre qual delas prevalece.

Nas últimas décadas, então, os dois termos - decolonização e globalização estão cada vez mais ao centro das reflexões críticas sociais e literárias, e são debatidos, em particular, por meio da intervenção crítica de pensadores que sublinham a natureza colonial do próprio conceito de modernidade. Modernidade, para esses estudiosos (alguns dos quais, como Walter Mignolo, Enrique Dussel e Aníbal Quijano, pertencem ao projeto Modernity/Coloniality Research Program), é uma noção inextrincavelmente ligada à conquista da América?

Como escrevem Walter Mignolo e Madina Tlostanova (2014), aquela modernidade que era associada, já no sentido mesmo do termo, à ideia de renovação e de novidade, inscrita, por exemplo, no termo "Renascimento", coincidia substancialmente com a colonização por parte dos europeus não só de um enorme território até então desconhecido, as Américas, mas também com uma simultânea colonização do tempo, que relegava - em oposição ao percurso europeu "luminoso", racional e "progressista" indicado pelo termo "Renascimento" - os "não modernos" a uma longa série de Idades Médias como única temporalidade a eles consentida.

Em nome de uma pretensa neutralidade do saber do homem branco, europeu, cristão - neutralidade que o sociólogo colombiano Santiago Castro-Gómez definiu como o "ponto zero" de observação e conhecimento - cancelaram-se as diferenças culturais para transformá-las em diferenças coloniais. Com a colonização das Américas, de fato, como bem explica o intelectual peruano Aníbal Quijano (2014), astecas, maias, incas, quéchuas

\footnotetext{
${ }^{6}$ Um possível exemplo é a importância central, nas argumentações de um dos expoentes máximos da reflexão pós-colonial, o estudioso anglo-indiano Homi K. Bhabha, de pensadores caribenhos (Aimé Césaire, Derek Walcott, Edouard Glissant), de teóricos chicanos, e de outros pensadores que colocaram no centro da própria reflexão a "descoberta da América" e a relação com o "selvagem". Sobre esse assunto remeto aos meus capítulos "ImmagiNazione" e "Babele nell'arcipelago antillano" no livro La Babele Postcoloniale (DE CHIARA, 2017). No meu livro Oltre la gabbia. Ordine coloniale e arte di confine (DE CHIARA, 2018 [2005]), a primeira seção inteira é uma viagem literária e teórica (Salman Rushdie, Robert Viscusi, Fernández Retamar, Carlos Fuentes, Guillermo Gómez-Peña) que se desenrola em torno da centralidade da figura de Cristóvão Colombo e da descoberta das Américas pelo pensamento da modernidade pós-colonial. Remeto também à esplêndida análise do evento da "descoberta" de Colombo oferecida por Serge Gruzinski (1991 [1990]) em La guerra delle immagini. Da Cristoforo Colombo a Blade Runner. ${ }^{7}$ Para as intervenções teóricas mais significativas desses pensadores é uma referência útil a coletânea de ensaios traduzidos em italiano, organizada por Gennaro Ascione (2014), America latina e modernità. L'opzione decoloniale: saggi scelti.
} 
etc. tornaram-se simplesmente índios; na África, axante, iorubá, zulu, congo, bacongo etc. tornaram-se simplesmente negros. Isto é, as diferenças culturais foram transformadas em diferenças raciais, para que se pudesse construir uma hierarquia de utilidade imediata ao nascente sistema capitalista europeu ${ }^{8}$.

Também o conhecimento, a partir do século XVII, é hierarquizado. O conhecimento da Europa ocidental passa a se identificar "como modernidade e racionalidade", ou melhor, a modernidade se torna "um produto exclusivamente europeu" (QUIJANO, 2014, p. 81). Como também reforça o estudioso José Saldívar, a classificação etnorracial das Américas e do mundo ("embalsamação das identidades”) andou lado a lado com a classificação das línguas e dos saberes, coisa que fez da epistemologia do Renascimento o instrumento para estabelecer saberes ou suprimi-los .

Os saberes colocados à parte pela "razão" europeia tornam-se aqueles saberes "subalternos" que, para conceituá-los, Saldívar chama em causa Michel Foucault e a sua famosa definição de "saberes sujeitados" ("subjugated knowledges"): ou seja, de um lado, os conteúdos históricos que foram sepultados ou traduzidos em uma sistematização funcional qualquer; de outro, por "saberes sujeitados" entende-se aqueles saberes que foram aviltados e tidos como não à altura do seu encargo ou pouco refinados; saberes ingênuos, colocados no grau mais inferior da hierarquia, abaixo do nível requerido de

\footnotetext{
${ }^{8}$ José Saldívar (2012, p. 8) reporta do ensaio de Quijano e Wallerstein (1992), “Americanity as a Concept, or the Americas in the Modern World-System", uma iluminadora definição para se compreender o quanto as diferenças raciais são, e foram, instrumentais para forjar o tipo de economia moderna. Esses são, na verdade, confinamentos impostos, em parte, pelo poder colonial, mas também em parte por nós mesmos, para associar a nossa identidade a uma local específico e um nível específico no interior do estado. Mas as identidades étnicas são sempre construtos ligados a uma instância temporal específica e, portanto, sempre mutáveis. Em todo caso, as principais categorias atuais de diferenciação étnica nas Américas e no mundo (Nativos Americanos ou Indígenas, Pretos ou Negros, Brancos ou Crioulos/Europeus, Mestiços ou outros nomes dados às assim chamadas categorias mistas) são todas categorias que não existiam antes do sistema-mundo moderno, e constituem a Americanidade. Tornaram-se a base cultural do sistemamundo como um todo.

9 "Em paralelo à classificação etnorracializada das Américas e do mundo (embalsamação das identidades), o projeto colonial nas Américas também classificou línguas e conhecimento. A epistemologia do Renascimento europeu foi, portanto, assumida como a perspectiva natural a partir da qual o conhecimento poderia ser descrito e suprimido" (SALDÍVAR, 2012, p. 9). Saldívar refere-se aqui ao trabalho de Walter Mignolo (2000b), Local Histories/Global Designs: Coloniality, Subaltern Knowledges, and Border Thinking. Citação original: "[P]arallel to the ethno-racialized classification of the Américas and the world (the embalming of identities), the colonial project in the Américas also classified languages and knowledge. The epistemology of the European Renaissance therefore was assumed to be the natural perspective from which knowledge could be described and suppressed".
}

Revista X, v. 16, n. 1, p. 175-193, 2021. 
conhecimento (FOUCAULT, $1980^{10}$, citado por SALDÍVAR, 2012, p. 76-77).

A modernidade então se revela abertamente como um sistema de poder de natureza colonial, um esquema, ou matriz, que Aníbal Quijano define como patrón de poder, ou seja, colonialidade do poder. Trata-se essencialmente de compreender o papel central que a ideia de raça reveste na classificação social da população do mundo. Dentro desse sistema, as novas identidades socio-históricas espelhavam as exigências do capitalismo emergente: isto é, nessa nova classificação, os brancos eram a parte patronal e assalariada; os negros eram a parte reduzida à escravidão, mão de obra gratuita para o sistema capitalista; os indígenas eram a parte destinada à servidão, parte não assalariada. Essa ligação entre raça e trabalho tornava-se um precioso instrumento da colonialidade do poder. Escreve Quijano:

Aquele elemento fundamental específico do novo esquema de poder mundial baseado na ideia de raça e na classificação social racial da população mundial - que se manifestava na distribuição racial do trabalho, na imposição de novas identidades geoculturais raciais, na concentração do controle dos recursos produtivos e do capital como relações sociais, incluindo o salário como privilégio da whiteness - é ao que essencialmente aqui se refere por meio da categoria colonialidade do poder, elemento que incide sobre toda distribuição da população mundial. Por isso, não obstante a "raça" e as relações sociais "racistas" na vida cotidiana da população do mundo tenham representado a expressão mais visível da colonialidade do poder durante os últimos quinhentos anos, a implicação histórica mais significativa foi o surgimento de um poder mundial capitalista moderno/colonial eurocêntrico com o qual ainda hoje convivemos (QUIJANO, 2014, p. 77, grifos no original).

Nesse sentido, como sugere o intelectual venezuelano Fernando Coronil, a biografia do capitalismo seria totalmente reescrita, já que o colonialismo não representa nessa história apenas um detalhe, um episódio ocorrido alhures, mas sim um elemento intrínseco ao desenvolvimento mesmo do capitalismo. Na verdade, expor a violência intrínseca à formação do capitalismo torna-se um ato necessário:

Como se descobrissem os estratos submersos de um palimpsesto, recuperar essa história reconduzirá à superfície as cicatrizes do passado cobertas pela maquiagem das histórias sucessivas e tornará mais visíveis também as feridas ocultas do presente. Uma abordagem que privilegia a relação constitutiva entre capitalismo e colonialismo nos permite reconhecer os papéis fundamentais desenvolvidos pelo trabalho e pela

\footnotetext{
${ }^{10}$ No Brasil, o texto de Foucault (2005) que apresenta o conceito "saberes sujeitados" foi publicado no volume Em defesa da sociedade: curso no Collège de France (1975-1976). [N. T]
}

Revista X, v. 16, n. 1, p. 175-193, 2021. 
natureza colonial na formação do mundo moderno. [...] [A] partir dessa perspectiva, a modernidade capitalista aparece desde o início como resultado de transações transcontinentais cujo caráter efetivamente global começou apenas com a Conquista e com a colonização das Américas (CORONIL, 2014, p. 128).

Coronil contesta as retóricas entusiastas de uma globalização entendida como feliz integração planetária, construção de uma "vila global", já que esse fenômeno, longe de ser novo, é na realidade o efeito não apenas de antigos processos, como trânsitos e trocas comerciais transcontinentais, reconectáveis séculos atrás à expansão capitalista nascida da colonização, mas é também o efeito de migrações em escala mundial, das quais derivaram numerosas e imprevistas trocas transculturais. Para Coronil, que insiste na passagem do eurocentrismo àquilo que denomina globocentrismo, a globalização neoliberal cria subreptícias formas de unificação, operando, na realidade, sobre assimetrias:

Contrariamente ao eurocentrismo típico dos discursos ocidentais do passado, que opera estabelecendo uma diferença assimétrica entre o Ocidente e os seus outros, o "globocentrismo" e os discursos dominantes da globalização neoliberal escondem a presença do Ocidente e ocultam a dimensão pela qual este último continua a depender da submissão dos seus outros e da natureza (CORONIL, 2014, p. 123).

A colonialidade do poder a respeito da qual insiste Quijano, ligando-a à relação raça $\mathrm{x}$ trabalho, é então desnudada, retraçando justamente uma biografia diversa do capitalismo, como auspiciado por Coronil, a fim de que se possa melhor compreender também a formação do saber moderno e das suas disciplinas. A colonialidade do poder inaugurou de fato um enquadramento evolucionista da história, que colocou "todos os não europeus, em relação aos europeus, em uma cadeia histórica contínua que vai de 'primitivo' a 'civilizado', de 'irracional' a 'racional', de 'tradicional' a 'moderno', de 'mágico-mítico' a 'científico"”; o não europeu podia apenas aspirar, se tanto, a ser europeizado ou "modernizado" (QUIJANO, 2014, p. 82).

\section{BORDERLANDS: EPISTEMOLOGIAS DE FRONTEIRA E TRANSAMERI- CANIDADE}

No entanto, essas nítidas separações que a colonialidade do poder impõe às pessoas e ao mundo todo são uma ilusão que não pode se sustentar se se consideram as interações sempre constantes entre os povos, antigos e recentes, ocorridas por meio das rotas comerciais, dos eventos militares, das ocupações, das usurpações, da expansão Revista X, v. 16, n. 1, p. 175-193, 2021. 
capitalista com suas rotas transcontinentais, das enormes migrações que vêm desde sempre caracterizando a história do mundo. Da reflexão sobre contínuas interações culturais entre terras e gentes, a história da americanidade pode, por exemplo, reescrever-se à luz daquilo que José Saldívar definiu como transamericanidade.

As perspectivas teóricas que emergiram, nessas últimas décadas, das terras de fronteira (borderlands nos EUA, ou seja, aquele território que geograficamente ocupa o sudoeste estadunidense na fronteira com o México), junto à criatividade artísticoliterária que dela brotou - a cultura chicana (mexicana-americana) é um exemplo mostram claramente como os territórios de fronteira se qualificam como perfeitos espaços experimentais sobre os quais o pensamento decolonial pode refletir de maneira mais ampla (SALDÍVAR, 2012, p. 11). O brilhante teórico e artista performático chicano Guillermo Gómez-Peña, por exemplo, definiu a fronteira como um verdadeiro laboratório artístico, enquanto que em The New World (B)order, de 1996, representou os Estados Unidos como um território que se transformou rapidamente em uma enorme zona de fronteira, uma sociedade híbrida, uma raça mestiça; um processo que é irreversível (GÓMEZ-PEÑA, 1996, p. 67). Nessa borderización incessante dos territórios, o artista pode ver (como sugeriu o estudioso Roger Bartra) aquilo que aos outros não é imediatamente evidente: o fato, por exemplo, de que a América Latina não termina exatamente na fronteira com os Estados Unidos, mas se insinuou completamente no território anglo, acabando por ocupar todos os seus espaços, do cultural ao sociopolítico e econômico ${ }^{11}$ (BARTRA, 1993, p. 11).

Falar de borderlands significa, inevitavelmente, recuperar sobretudo o célebre Borderlands/La Frontera. The New Mestiza, de Gloria Anzaldúa (1987), texto teóricopoético que, no ano de sua publicação, deu um excepcional impulso à reflexão e à releitura do conceito de fronteira ${ }^{12}$. Voz teórica de maior referência para as borderlands do sudoeste estadunidense, Anzaldúa propôs a sua teoria da fronteira, border theory, afirmando com orgulho programático o pertencimento a uma cultura claramente bilíngue, na qual as contaminações e as misturas do spanglish (um misto de inglês e de espanhol) desafiam a ideia de uma presumida originalidade e pureza das diversas culturas, conclamando a identidade cultural como identidade híbrida, sempre na fronteira entre coisas e mundos ${ }^{13}$.

As teorias da fronteira de Gloria Anzaldúa inauguraram, como reconhece a estudiosa chicana Alicia Gaspar de Alba, um verdadeiro modelo no campo dos estudos de

\footnotetext{
${ }^{11}$ Dediquei uma acurada panorâmica sobre o artista na primeira parte de Oltre la gabbia. Ordine coloniale e arte di confine (DE CHIARA, 2018 [2005]).

${ }^{12}$ Remeto a "La frontiera e il filo spinato: Borderlands di Gloria Anzaldúa" (DE CHIARA, 2001).

${ }^{13}$ Para aprofundar a questão do spanglish remeto a Nuevas voces sobre el Spanglish: una investigación polifónica, volume organizado por Silvia Betti e Enrique Serra Alegre (2016).
}

Revista X, v. 16, n. 1, p. 175-193, 2021. 
americanística das últimas décadas, um modelo que permite "raciocinar e escrever sobre as múltiplas histórias, línguas, gêneros e realidades raciais que convergem naquele vastíssimo campo de milho da vida e cultura 'Americana"' (GASPAR DE ALBA, 2014, p. xviii).

Nas borderlands o atravessamento e a mistura entre etnias, costumes, linguagens é uma constante, e é aqui que se manifesta mais claramente o fato de cada identidade ser híbrida por natureza. Como também já havia insistido nos anos 1920 José Vasconcelos ministro da Cultura mexicano que teorizou um mundo por vir que é e será inevitavelmente o fruto de misturas de gentes -, a mestiçagem, explica Anzaldúa, está na raiz das culturas de todo lugar, e a figura do mestizo e da mestiza são origem e destino do mundo ${ }^{14}$. Propondo em termos fundamentalmente feministas ${ }^{15}$ a sua visão da identidade como produto de elementos que se mesclam desde tempos e lugares distantes, Anzaldúa recorre ao conceito asteca de nepantilismo:

Em um estado constante de nepantilismo mental, uma palavra asteca que significa partido ao meio, la mestiza é um produto da transferência de valores culturais e espirituais de um grupo para outro. Ser tricultural, monolíngue, bilíngue, ou multilíngue, falando um patois, e em um estado de transição constante, a mestiza se depara com o dilema das raças híbridas: a que coletividade pertence a filha de uma mãe de pele escura? (ANZALDÚA, 2005, p. 705) ${ }^{16}$.

\footnotetext{
${ }^{14} \mathrm{O}$ nome de José Vasconcelos está indissoluvelmente ligado ao livro-manifesto La raza cósmica, de 1948, no qual formula as suas teorias sobre a identidade híbrida e sobre um futuro compósito e mestiço.

${ }^{15}$ Em um estudo anterior dedicado às Borderlands defini esse olhar feminista como feminismo da hibridização: "Nenhum pertencimento e todos os pertencimentos, nenhuma casa e todas as casas: esse é o estado de viagem contínua no qual se move la mestiza, estrangeira no lugar onde se fala uma só língua, uma só cultura, um só desejo, uma só união [...] um feminismo da hibridização que vai além de apenas se deter sobre a necessidade da diferença, para mostrar os infinitos modos pelos quais as próprias diferenças se complicam ao se articularem entre si" (DE CHIARA, 2001, p. 124). Sobre Borderlands, veja-se também Mappings. Feminism and the Cultural Geographies of Encounter, de Susan Stanford Friedman (1998, p. 94). De particular interesse a introdução escrita por Norma Cantú e Aída Hurtado (2012) para a quarta edição de Borderlands, sobre o impacto crítico desse texto, mais de vinte anos após sua publicação, nos estudos de fronteira.

${ }^{16}$ In a constant state of mental nepantilism, an Aztec word meaning torn be- tween ways, la mestiza is a product of the transfer of the cultural and spiritual values of one group to another. Being tricultural, monolingual, bilingual, or multilingual, speaking a patois, and in a state of perpetual transition, the mestiza faces the dilemma of the mixed breed: which collectivity does the daughter of a darkskinned mother listen to? (ANZALDÚA, 1987, p. 78). [No texto original, a autora incluiu essa citação em inglês e sua tradução para o italiano, que aqui substituímos pela tradução em português. N. T.]
}

Revista X, v. 16, n. 1, p. 175-193, 2021. 
O pensamento de Anzaldúa é profundamente decolonial ao recusar o terrorismo cultural imposto pela cultura branca estadunidense e ao denunciar o estado de esquizofrenia identitária ao qual o colonizador constringe o colonizado. Esse pensamento tornou-se imediatamente central também para o feminismo chicano, dado que Anzaldúa relê as experiências identitárias das mulheres chicanas criadas no sul do Texas (na fronteira entre duas culturas, a mexicana e a estadunidense), fazendo da fronteira entre esses dois países uma potente metáfora de todos os tipos de atravessamentos e traspassamentos: atravessamentos de limites geopolíticos, sexuais, deslocamentos sociais, cruzamentos e alianças por afinidades remotas, em suma, atravessamentos e correspondências necessárias para sobreviver em contextos linguísticos e culturais múltiplos (CANTÚ; HURTADO, 2012, p. 5-6).

Reler as histórias territoriais e culturais, coletivas ou singulares, a partir da perspectiva da fronteira e da ideia de contínua transição da identidade (nepantla) significa abrir perspectivas transnacionais que reescrevem a história das nações insistindo na ideia de intercâmbio contínuo entre as culturas e as linguagens e sobre a porosidade das fronteiras. Trata-se de perspectivas que o estudioso de origem argentina Walter Mignolo definiu como border epistemologies, epistemologias da fronteira, e que emergem precisamente destes territórios porosos para desafiar as narrativas monolíticas e limitadamente míopes expressas pelas histórias nacionais.

Inspirando-se justamente no olhar de fronteira inaugurado por Gloria Anzaldúa e na esteira do pensamento de Fernando Ortiz sobre a transculturation ${ }^{17}$, José Saldívar (2012, p. 183) impulsiona à reformulação do conceito de América para se restituir uma imagem transgeográfica da cultura americana ${ }^{18}$. Escrevendo a palavra América com acento ${ }^{19}$, o estudioso quer destacar a centenária presença hispânica no território estadunidense, no Caribe e na América do Sul. Essa presença centenária sofreu um cancelamento sistemático e um ocultamento programático por parte do poder hegemônico branco e anglófono até se tornar um elemento praticamente estranho à ideia de América. E se o sistema colonial inventou categorias inteiras de diferenciação étnica que antes não existiam (por exemplo, Nativos Americanos ou Indígenas, Pretos ou Negros, Brancos ou Crioulos/Europeus,

\footnotetext{
${ }^{17} \mathrm{O}$ neologismo de Ortiz, que tende a substituir o termo acculturation, melhor se adapta, segundo ele, a explicar as complexas transmutações culturais verificadas em Cuba (ORTIZ, 1995, p. 9798, citado por SALDÍVAR, 2012, p. 231).

${ }^{18}$ Aqui gostaria também de sugerir a leitura dada por Serge Gruzinski (1991 [1990]) da incrível extensão do poder e do raio de ação da "hispânica" monarquia católica entre o fim do século XVI e o início do XVII no globo terrestre, poder que leva Gurzinski a falar dela como monarquia "planetária". ${ }^{19}$ Diferente da ortografia do inglês, língua em que o autor escreve, e que grafa America sem acento. Ver exemplo na citação original na nota 10 deste texto [N. T.].
} 
Mestiços e outros), úteis para criar hierarquizações para fins coloniais, é preciso então recordar que todas constituem aquele tecido compósito que é a Americanidade.

Nessa reformulação do mundo por meio de novos modos de pensar, ou seja, novas epistemologias, indaga-se também sobre a natureza colonial inserida em linguagens que se tende a considerar neutras, objetivas, desinteressadas. Por exemplo, as linguagens das teorias sociais e das teorias literárias. Trata-se, na realidade, de linguagens que evocam implicitamente as hierarquizações estabelecidas pela colonialidade do poder, que dizem respeito, como falado antes, também ao regime epistemológico, ou seja, o campo do saber e do conhecimento. A esse propósito, Saldívar detém-se sobre uma questão que não se refere simplesmente ao âmbito literário, mas investe a condição mesma do saber e da relação com o mundo. Trata-se da questão do realismo e do assim chamado "realismo mágico", marvelous realism, que foi a chave estilística de narradores latino-americanos como Gabriel García Márquez, Alejo Carpentier, Juan Rulfo, e outros. É uma questão que se repensa à luz das dinâmicas de poder que entram em jogo na definição daquilo que se considera real e daquilo que não o é. Na esteira das intuições de Louis Althusser (Ideologia e aparelhos ideológicos de Estado, de 1970), Saldívar recorda que aquilo que é considerado "realismo" representa apenas uma versão específica da realidade, ou seja, aquela da ideologia hegemônica, "[...] o modo ideologicamente hegemônico de conceber e expressar nossa relação com os mundos naturais e sociais à nossa volta. Em outras palavras, $[\ldots]$ o realismo funciona ideologicamente: ele se oferece como reflexão neutra do mundo quando este é apenas um dos meios de evocá-lo" (SALDÍVAR, 2012, p. 226) ${ }^{20}$.

Colocando em dúvida o conceito de "realismo mágico" como estilo que contradistingue a literatura latino-americana (e que forneceu uma importante referência conceitual para um tanto de teorias pós-modernas), Saldívar prefere recorrer ao termo transmodernism, um neologismo do teórico argentino-mexicano Enrique Dussel. Dussel, como alternativa à noção eurocêntrica de pós-modernidade, insiste sobre os cruzamentos múltiplos e as contaminações imprevistas entre as culturas, incluindo as mais distantes no tempo e no espaço, e coloca as "histórias" transmodernistas em estreita relação com as filosofias da libertação do Sul Global. Em suma, está em jogo disputar o real, avançar com outras instâncias sobre o real que não respondam àquelas já predispostas pela empresa colonial e epistemológica eurocêntrica ${ }^{21}$.

\footnotetext{
20 " [...] the ideologically hegemonic way to conceive and express our relationship to the natural and social worlds around us. In other words, [...] realism functions ideologically: it offers itself as neutral reflection of the world when it is but one way to conjure the world".

${ }^{21}$ Sobre a relação entre transmodernismo e ética da teologia da libertação, veja-se Saldívar (2012, p. 201).
}

Revista X, v. 16, n. 1, p. 175-193, 2021. 
Um dos desafios colocados hoje às ciências sociais é, então, a possibilidade de sair das suas coordenadas eurocêntricas, como sublinha Catherine Walsh (2014, p. 167-169), intelectual do Equador. Por exemplo, um dos caminhos a serem percorridos por uma séria reviravolta decolonial é a revalorização daqueles conhecimentos e saberes que por séculos foram tidos como não conhecimentos, interrogando também o papel desempenhado pelas universidades como sedes do saber. O exemplo do intelectual português Boaventura de Sousa Santos, com a criação de uma Universidade Popular dos Movimentos Sociais, é reportado por Catherine Walsh como modelo de uma nova modalidade do saber, aquele de uma "epistemologia do sul" que possa restituir credibilidade aos novos movimentos sociais contra-hegemônicos, por exemplo, aqueles dos povos indígenas ${ }^{22}$ (WALSH, 2014, p. 161).

\section{COLONIALIDADE DO PODER E OUTROS SUIS: HISTÓRIAS ITALIANAS}

As reflexões de Quijano e do grupo de pesquisa latino-americano sobre a colonialidade do poder revelaram-se certamente úteis para abrir perspectivas diversas sobre faixas geográficas que se encontram há séculos prisioneiras da oposição epistemológica entre norte e sul do mundo. Com o olhar voltado à situação italiana, uma coletânea de ensaios de 2012 retoma as intuições de Quijano sobre a relação entre raça e trabalho. Trata-se do livro organizado por Miguel Mellino e Anna Curcio (2012), La razza al lavoro, que indaga justamente sobre essa conjunção à luz da recente história italiana. Nas últimas décadas, na Itália, no que diz respeito às políticas trabalhistas e imigratórias, a narrativa nacional acabou por se revelar como a tentativa falida de compor em unidade um território assimétrico, absolutamente não homogêneo e, sobretudo, assinalado por um racismo silencioso que opera agora, como foi no passado, sob várias formas. Porque justamente o racismo se esconde frequentemente sob outros nomes, não se declara abertamente, para não contradizer a imagem que as modernas nações europeias amam promover de si como territórios livres e liberais, emancipados e progressistas. As inflexões "locais" da questão italiana, conjugadas às reflexões teóricas pós-coloniais de um cenário globalizado, mostram claramente o racismo como o - para dizer com as palavras do crítico Homi Bhabha - "suplemento" da nação e da sua narrativa.

Nas modernas dinâmicas do trabalho, radicadas em uma economia de interconexões totalmente despreocupadas de limites territoriais, aflora de fato uma intrínseca ligação ideológica com o racismo europeu. O racismo, formidável instrumento propulsor, já desde o século XVIII, das empresas coloniais nas quais estavam envolvidas as várias potências

\footnotetext{
${ }^{22}$ Sobre o indigenismo, vejam-se as reflexões em De Chiara (2019b).

Revista X, v. 16, n. 1, p. 175-193, 2021.
} 
europeias, continua a funcionar, também hoje, estrategicamente, de forma mais ou menos oculta, na definição de uma cartografia do trabalho e dos seus percursos.

No presente da política italiana reafloram velhos fantasmas racistas que já estavam presentes nas espinhosas questões da Itália pós-unitária, cortada ao meio pelo antimeridionalismo ${ }^{23}$; da Itália colonialista nascida do sonho imperial de Mussolini; da Itália esvaziada primeiro pelas migrações do fim do século XIX em direção a terras distantes e, depois, impulsionada pela correnteza de trabalhadores que se deslocavam do Sul ao Norte nos anos 1950.

Um não nomeado racismo anima também a relação entre as políticas territoriais e a imigração estrangeira. Aqui se explica uma das gradações do belo título da coletânea: o racismo está em obra, no trabalho, quando se trata de estabelecer como canalizar a força de trabalho dos imigrados que, sobretudo a partir dos anos 1980, chegaram e continuam chegando no solo italiano. Essas novas chegadas mudaram, na Itália, o cenário trabalhista, no sentido de que o próprio mercado de trabalho mudou completamente de rosto quando pôde colocar o outro para trabalhar, o portador de uma outra raça. Mas essa investigação no atual mundo do trabalho, no fundo, desnuda também a própria história do capitalismo moderno, como sublinham Anna Curcio e Miguel Mellino em sua articulada introdução. Nos já distantes tempos em que nascia e se consolidava o trabalho moderno, aquelas primeiras formas do modelo capitalista-burguês da produção, do consumo e da circulação de matérias-primas e de mercadorias eram, com efeito, inequivocamente conectadas à organização colonial estabelecida pelas potências europeias. Essas potências coloniais desejaram e souberam colocar as populações colonizadas para trabalhar, criando, a partir da própria posição de hegemonia, justificativas incontestáveis para declarar o outro naturalmente predisposto ao assujeitamento; a raça, como novo conceito em si, ligado à ideia de uma segura rastreabilidade científica quanto à inferioridade ou superioridade de um tipo de homem em relação a outro, fornecia um excelente instrumento, e um nomechave, para assinalar a priori a um povo o seu pretenso destino.

Ao negro africano, trazido como animal acorrentado ao longo das rotas atlânticas, coube, em nome da raça, não apenas o terrível destino de ocupar o último grau da escala que definia o que era um homem e o que não era, mas, também, de funcionar como cobaia para o moderno laboratório capitalista do trabalho; aquelas infames plantações nas quais os escravos negros, com a sua mão de obra gratuita, enriqueciam os escravagistas dos estados civis do Sul do território americano, forneceram de fato um tipo de modelo ideal

\footnotetext{
${ }^{23}$ Diz respeito à ideia preconceituosa de que o sul da Itália - pessoas, cultura, modo de vida - é inferior ao norte [N. T.].
} 
para a organização do trabalho na fábrica. Mas a ideia de um lugar de reclusão forçada e de exploração também serviu, em solo europeu, quando o delírio de Hitler demonizou o hebreu a ponto de confiná-lo nos campos de concentração; e ainda serve, ao italiano de hoje e aos muitos europeus que vivenciam diretamente as "invasões" de refugiados, marginalizados em busca de trabalho, para "represar" o imigrado e condená-lo, em sua ameaçadora veste de clandestino, a lugares que se chamam "centros", e que assumem de tanto em tanto novos nomes para deter, identificar e expelir.

O imigrado (como notam Giorgio Grappi e Costanza Margiotta em seus respectivos ensaios contidos em La razza al lavoro) questiona direta e radicalmente o conceito de cidadania ao qual, nestas últimas duas décadas, ofereceu-se respostas subreptícias e criminosas até mesmo em matéria jurídica, respostas que contribuíram para tornar a existência do imigrado vulnerável, precária, sequestrável. Sob o denominador comum da clandestinidade, o imigrado de hoje recorda a vulnerabilidade do trabalhador que emigrava do sul para procurar trabalho e moradia nas cidades industrializadas do norte, como Turim, Gênova, Milão, já a partir dos nos 1950. A astúcia sádica das políticas territoriais de então, que eram cúmplices dos discursos antimeridionalistas difundidos há um século, contribuíam para alimentar um mercado de trabalho que, como explica Enrica Capussotti, sempre explorou a posição de fragilidade do trabalhador. De um lado se criava um repositório de trabalho a baixo custo, de outro nascia uma nova figura de criminoso: o clandestino, o emigrante sem residência. $\mathrm{O}$ caso de Lampedusa ${ }^{24}$, por exemplo, que já há quase vinte anos é sintomático na Itália quanto às políticas de imigração (na imediata concretude de fazer frente aos desembarques dos refugiados e à primeira acolhida, à defesa das fronteiras do território de chegada e ao controle das fronteiras dos territórios de proveniência dos imigrados), tem sido analisado por Gianluca Gatta também como paradoxo de um antimeridionalismo, aquele da Lega Nord ${ }^{25}$, que em Lampedusa rende mais discursos ${ }^{26}$.

\footnotetext{
${ }^{24}$ Ilha siciliana onde são frequentes os desembarques de refugiados oriundos do norte da África [N. T.].

${ }^{25}$ Liga Norte, em português. Partido regionalista de extrema-direita do norte da Itália [N. T.].

${ }^{26}$ Sobre a condição dos migrantes desembarcados em Lampedusa sugiro a tocante leitura de Angela Lanza (2014), La storia di uno è la storia di tutti. O volume contém um testemunho de Enza Malatino e o texto da Carta de Lampedusa. Lampedusa, com os trágicos desembarques e a memória marinha dos inumeráveis por afogamento, tornou-se recentemente também fonte de uma verdadeira "estética lampedusana" (IANNICIELLO; QUADRARO, 2015). [A Carta de Lampedusa é um documento elaborado em 2014 por representantes da sociedade civil, propondo um novo paradigma para se lidar com as realidades migratórias. O documento começou a ser elaborado depois do naufrágio em que morreram mais de 400 pessoas vindas do norte da África quando tentavam chegar à Itália [N. T.].
} 
Também se encontram, porém, cenários nos quais a palavra raça carrega outros signos: o trabalhador meridional nos anos 1960 e 1970 se organizava em lutas operárias, emitindo uma nota dissonante nas políticas daqueles anos, assim como hoje os movimentos antirracistas e as demandas trabalhistas dos imigrados criaram novas sinergias e significações culturais. Chiara Bonfiglioli coloca como exemplo ainda os novos debates nascidos nos movimentos feministas, partindo do corpo vitimizado da "estrangeira", sobre o qual pesa o fardo de um imaginário carregado: aquele, otimamente ilustrado por Caterina Miele, das ex-colônias, a Líbia e a Etiópia, que o italiano fascista quer dobrar ao prestígio da raça.

Nessa condenação partilhada pelo atraso e pelas resistências da legislação italiana concernente às novas configurações da cidadania em um contexto decididamente multicultural, Sandro Mezzadra recorda que já Antonio Gramsci lia o multiculturalismo em ato como uma das emergências críticas de então, antecipando a atual necessidade intelectual e política de se haver com questões como a da fronteira, da territorialidade, do pertencimento identitário, da "diferença" e da hibridização cultural. A pergunta à qual precisar-se-ia dar enfim uma séria resposta se perfila, na realidade, como uma pergunta sobre a "pedagogia" em si, em sentido lato, de uma nação: com quais elementos, pergunta Luca Queirolo Palmas, pode-se formar, seja na escola, seja no cotidiano, o cidadão de uma Europa "mestiça"? Como tornar-se cidadão "responsável" depois do trauma (para retomar as perplexidades de Renate Siebert em seu ensaio) de se descobrir ex-colonizador e racista?

As disciplinas ditas humanísticas têm um dever especial nesse percurso delicado, mas urgente, que implica uma plena consciência das assimetrias econômicas de um país, pois as assimetrias econômicas, em qualquer sociedade, produzem sempre, tanto ontem como hoje, um imaginário que é feito de medo, lugares-comuns, mesmo se às vezes fascinantes. E acaba-se então por contar uma mesma história: a da ameaça do bandido, emblema de um sul que se subtraía, sombrio e desafiador, à unificação da Itália - que Pietro Germi imortalizou em seu filme de 1952, O bandido da Cova do Lobo -, a da ameaça do cigano, o "estrangeiro" absoluto, relegado às margens do viver civil, junto àqueles mesmos aterros onde facilmente também se perde a nossa humanidade. Trata-se de uma ameaça que continua a aparecer em cada lugar do nosso planeta, em formas diversas, mas sempre inscritas no jogo de forças entre hegemônico e subalterno, como mostram a estética colonial e pós-colonial; dos memoráveis "selvagens" imortalizados em narrativas "modelo" da Europa moderna como, por exemplo, a figura de Calibã em A tempestade, de Shakespeare, ou a figura de Sexta-Feira (Friday) no romance Robinson Crusoé, de Daniel Defoe, o imaginário moderno nunca cessou de parir figuras "outras" sobre as 
quais projetar o lado obscuro daquilo que não se deseja, definitivamente, reconhecer como parte de $\mathrm{si}^{27}$.

\section{REFERÊNCIAS BIBLIOGRÁFICAS}

ANZALDÚA, Gloria. Borderlands/La Frontera. The New Mestiza. San Francisco: Aunt Lute Books, 1987.

ANZALDÚA, Gloria. La conciencia de la mestiza/Rumo a uma nova consciência. Rev. Estudos Feministas, Florianópolis, v. 13, n. 3, p. 704-719, Dez. 2005. Disponível em: http://dx.doi.org/10.1590/S0104-026X2005000300015. Acesso em: 23 jun. 2020.

ASCIONE, Gennaro (org.). America latina e modernità. L'opzione decoloniale: saggi scelti. Salerno: Arcoiris, 2014.

BARTRA, Roger. Introduction. In: Gómez-Peña, Guillermo. Warrior for Gringostroika. Minnesota: Graywolf Press, 1993.

BENNETT, Tony; GROSSBERG, Lawrence; MORRIS, Meaghan (ed.). New Keywords: A Revised Vocabulary of Culture and Society. Malden; Oxford; Carlton: Blackwell Publishing, 2005.

BETTI, Silvia; SERRA ALEGRE, Enrique (org.). Nuevas voces sobre el Spanglish: una investigación polifónica. New York: ANLE, 2016.

CANTÚ, Norma; HURTADO, Aída. “Breaking Borders/Constructing Bridges: TwentyFive Years of Borderlands/La Frontera. Introduction to the Fourth Edition". In: Anzaldúa, Gloria. Borderlands/La Frontera. The New Mestiza. San Francisco: Aunt Lute Books, 2012, p. 3-13.

CHAKRABARTY, Dipesh. The climate of history: Four Theses. Critical Inquiry, v. 35, n. 2, 2009.

CLIFFORD, James. Returns. Becoming Indigenous in the Twenty-First Century. Cambridge, MA: Harvard U. P., 2013.

CORONIL, Fernando. Natura del postcolonialismo: dall'eurocentrismo al globocentrismo [2000]. In: Ascione, Gennaro (org.). America latina e modernità. L'opzione decoloniale:

\footnotetext{
${ }^{27}$ Para outras perspectivas sobre a figura do "nativo" como objeto etnográfico, veja-se o já citado Oltre la gabbia. Ordine coloniale e arte di confine (DE CHIARA, 2018 [2005]) e "Nostalgie coloniali? Clifford racconta Ishi" (DE CHIARA, 2019b).
} 
saggi scelti. Salerno: Arcoiris, 2014.

CURCIO, Anna; Mellino, Miguel (org.). La razza al lavoro. Vicenza: Manifestolibri, 2012.

DE CHIARA, Marina. La Babele Postcoloniale. Napoli: Ad est dell'equatore, 2017.

DE CHIARA, Marina. Oltre la gabbia. Ordine coloniale e arte di confine. Milano: Meltemi, 2018 [2005].

DE CHIARA, Marina. La frontiera e il filo spinato: Borderlands di Gloria Anzaldúa. In: De Chiara, Marina. La traccia dell'altra. Scrittura, identità e miti del femminile. Napoli: Liguori, 2001.

DE CHIARA, Marina. Nostalgie coloniali? Clifford racconta Ishi. In: DE CHIARA, Marina (org.). Sud immaginari. Colonialità del potere, chicane ribelli, interferenze blues. Mantova: Universitas Studiorum, 2019b.

FOUCAULT, Michel. Two lectures. In: Power/Knowledge: Selected Interviews and Other Writings, 1972-1977. New York: Pantheon, 1980.

FOUCAULT, Michel. Em defesa da sociedade: curso no Collège de France (1975-1976). Tradução de Maria Ermantina Galvão. São Paulo: Martins Fontes, 2005.

FRIEDMAN, Susan Stanford. Mappings. Feminism and the Cultural Geographies of Encounter. New Jersey: Princeton U. P., 1998.

GASPAR DE ALBA, Alicia. [Un]Framing the "Bad Woman". Sor Juana, Malinche, Coyolxauhqui and Other Rebels with a Cause. University of Texas Press, 2014.

GÓMEZ-PEÑA, Guillermo. The New World (B)order. Prophecies, Poems \& Loqueras for the End of the Century. San Francisco: City Lights, 1996.

GRUZINSKI, Serge. La guerra delle immagini. Da Cristoforo Colombo a Blade Runner. Milano: SugarCo, 1991 [1990].

IANNICIELLO, Celeste; Quadraro, Michaela. Memorie Transculturali. Estetica contemporanea e critica postcoloniale. Napoli: UNIOR, 2015.

LANZA, Angela. La storia di uno è la storia di tutti. Roma: Iacobelli, 2014.

MIGNOLO, Walter. (Post)Occidentalism, (Post)Coloniality, and (Post)Subaltern Rationality. In: Afzal-Khan, Fawzia; Seshadri-Crooks, Kalpana (org.). The Pre- 
Occupation of Cultural Studies. Durham: Duke U. P., 2000a.

MIGNOLO, Walter. Local Histories/Global Designs: Coloniality, Subaltern Knowledges, and Border Thinking. Princeton: Princeton U. P., 2000 b.

MIGNOLO, Walter; TLOSTANOVA, Madina. Teorizzare dai confini: verso la geopolitica e la corpo-politica del sapere [2006]. In: Ascione, Gennaro (org.). America latina e modernità. L'opzione decoloniale: saggi scelti. Salerno: Arcoiris, 2014, p. 171-195.

ORTIZ, Fernando. Cuban Counterpoint: Tobacco and Sugar. Durham: Duke U. P., 1995.

QUIJANO, Aníbal; Wallerstein, Immanuel. Americanity as a Concept, or the Americas in the Modern World-System. International Social Science Journal, n. 134, 1992.

QUIJANO, Aníbal. Colonialità del potere ed eurocentrismo in America latina [2000]. In: Ascione, Gennaro (org.). America latina e modernità. L'opzione decoloniale: saggi scelti. Salerno: Arcoiris, 2014, p. 73-96.

RESTREPO, Eduardo; Rojas, Axel. Inflexión decolonial. Popayán, Colombia: Universidad del Cauca, Instituto Pensar, Universidad Javeriana, 2010.

SALDÍVAR, José. Trans-Americanity. Subaltern Modernities, Global Coloniality, and the Cultures of Greater Mexico. Durham \& London: Duke University Press, 2012.

VITALE, Marina. Changing Vocabularies in Cultural and Postcolonial Studies. Anglistica, n. 13, 2, 2009.

WALSH, Catherine. Sono possibili scienze sociali/culturali altre? Riflessioni sulle epistemologie coloniali [2007]. In: Ascione, Gennaro (org.). America latina e modernità. L'opzione decoloniale: saggi scelti. Salerno: Arcoiris, 2014, p. 167-169.

WILLIAMS, Raymond. Palavras-chave: um vocabulário de cultura e sociedade. Tradução Sandra Guardini Vasconcelos. São Paulo: Boitempo, 2007.

WILLIAMS, Raymond. Cultura e sociedade: de Coleridge a Orwell. Tradução Vera Joscelyne. Petrópolis: Editora Vozes, 2011. 